\title{
O Diretor de Turma e a Gestão Pedagógica nas Escolas Profissionais Inhamuenses
}

\author{
Gilmar Pereira Costa \\ Universidade Estadual do Ceará - UECE \\ Antonio Germano Magalhães Júnior \\ Universidade Estadual do Ceará - UECE
}

\begin{abstract}
Resumo
O Projeto Professor Diretor de Turma (PPDT) consiste em uma política educacional cearense que busca contribuir para a desmassificação do ensino, atuando em frentes como a redução do abandono e da infrequência e garantia do sucesso escolar. Constitui a organização e funcionamento das escolas estaduais de educação profissional (EEEPs) desde a implantação desta outra política no Ceará. A pesquisa responde à seguinte questão: como o PPDT contribui para a gestão pedagógica da escola? Desta forma, adotamos como objetivo central analisar como tal política interfere na gestão pedagógica das escolas profissionais situadas no Sertão dos Inhamuns. A investigação é norteada pela abordagem qualitativa e delineada como estudo de caso múltiplo, tendo como loci as escolas profissionais situadas nas cidades de Parambu e Tauá, pertencentes à microrregião citada, e como sujeitos 03 (três) professoras diretoras de turma em cada escola. As técnicas adotadas foram a entrevista semiestruturada e a observação sistemática. Os resultados indicaram que o projeto contribui positivamente para a gestão pedagógica das escolas profissionais, embora em cada uma das realidades hajam aspectos a serem melhorados em sua estrutura e funcionamento.
\end{abstract}

Palavra-chave política educacional; projeto professor diretor de turma; gestão pedagógica; escola profissional.

\begin{abstract}
The Teacher Class Director Project (PPDT) consists of an educational policy from Ceará that seeks to contribute to the demassification of teaching, acting on fronts such as reducing dropout and infrequency and guaranteeing school success. It constitutes the organization and functioning of state schools of professional education (EEEPs) since the implementation of this other policy in Ceará. The research answers the following question: how does the PPDT contribute to the pedagogical management of the school? Thus, we adopted as a central objective to analyze how such policy interferes in the pedagogical management of professional schools located in the Sertão dos Inhamuns. The investigation is guided by the qualitative approach and outlined as a multiple case study, with the professional schools
\end{abstract}


located in the cities of Parambu and Tauá, belonging to the aforementioned microregion as the locus, and as subjects (03) three principal teachers in each school. The techniques adopted were semi-structured interviews and systematic observation. The results indicated that the project contributes positively to the pedagogical management of professional schools, although in each of the realities there are aspects to be improved in its structure and functioning.

Key-word educational politics; class teacher teacher project; pedagogical management; vocational school.

\section{Introdução}

O Ceará, unidade da federação que tem se destacado em suas políticas educacionais, vivencia desde o ano de 2008 o Projeto Professor Diretor de Turma (PPDT), política educacional que se trata de um conjunto de ações comprometidas com a construção de uma escola que educa com base no binômio razão-emoção, atuando na ideia de desmassificação do ensino e consideração dos educandos e das educandas em suas diversidades (CEARÁ, 2010).

Pensando nos possíveis resultados oriundos desta política no cenário específico das escolas profissionais, a investigação nasceu a partir da seguinte questão-problema: como o PPDT contribui para a gestão pedagógica da escola? A pergunta principal trouxe à tona, algumas sub-questões: Como são tecidas as relações entre a direção de turma e a gestão pedagógica da escola? Quais os limites e possibilidades que este projeto apresenta na cotidianidade da escola?

O objetivo geral da investigação é analisar como tal política interfere na gestão pedagógica das escolas tipificadas como profissionais, situadas na região conhecida como Sertão dos Inhamuns. Como objetivos específicos, adotamos: descrever os papeis do projeto na política educacional do Ceará e caracterizar as relações entre esta política e a gestão pedagógica evidenciada por tais escolas, na aludida região.

0 artigo traz uma importante contribuição no que concerne à riqueza dos dados empíricos coletados na realidade de duas escolas, podendo servir como instrumento de leitura e reflexão a educadores, educadoras e estudantes das áreas da educação e das políticas públicas.

\section{Metodologia}

A pesquisa foi amparada nos pressupostos do paradigma fenomenológico, que enfatiza "o estudo das experiências vividas de cada um e a experiência humana com ênfase nos sentidos, interpretações, atividades e interações pessoais" (MOREIRA, 2004, p. 46).

No que se refere à abordagem, trata-se de um estudo qualitativo, que busca perceber o contexto da prática social dos sujeitos envolvidos diretamente com o problema definido. Neste sentido, é considerado "[...] o universo de significados, motivos, aspirações, crenças, valores e atitudes, o que corresponde a um espaço mais profundo das relações, dos processos e dos fenômenos" (MINAYO; GOMES, 2015, p. 21-22).

O delineamento empregado na pesquisa é o estudo de caso múltiplo. Gil (2010, p.37) pontua que tal tipo de pesquisa "[...] consiste no estudo profundo e exaustivo de um ou poucos objetos, de maneira que permita seu amplo e detalhado conhecimento [...]". 
0 estudo tem abrangência regional, envolvendo as duas escolas profissionais da microrregião conhecida como Sertão dos Inhamuns, tendo como loci da pesquisa a EEEP Joaquim Filomeno Noronha, situada na cidade de Parambu, e a EEEP Monsenhor Odorico de Andrade, situada em Tauá. Ambas são unidades de ensino médio que funcionam sob a jurisdição da Coordenadoria Regional de Desenvolvimento da Educação (CREDE 15), entidade regional da Secretaria da Educação Básica do Ceará (SEDUC).

Para a coleta dos dados, adotamos duas técnicas tidas como essenciais em nossa investigação: a entrevista semiestruturada com os sujeitos da pesquisa, visando apreender suas concepções acerca dos impactos do PPDT na gestão pedagógica das escolas profissionais; e a realização de observação sistemática em aulas do componente curricular: Formação para a Cidadania e Desenvolvimento de Competências Socioemocionais e de reuniões bimestrais de Conselho de Turma.

A análise dos dados se deu com base na análise de conteúdo. Como pontuam Minayo e Gomes, recorrendo a Bauer: "No divisor quantidade/qualidade das ciências sociais, a análise de conteúdo é uma técnica híbrida que pode mediar esta improdutiva discussão sobre virtudes e métodos" (BAUER, 2002 apud MINAYO; GOMES, 2015, p. 83). Na análise de conteúdo, as inferências são consideradas e apresentam relevância, uma vez que elas representam o que não é expressado nas opiniões e representações sociais dos sujeitos da pesquisa.

Para respaldar a pesquisa, submetemos nosso projeto ao Comitê de Ética em Pesquisa (CEP) da UECE, via Plataforma Brasil, que conferiu parecer favorável quanto aos seus aspectos éticos e metodológicos, no Parecer Consubstanciado do CEP/UECE no: 3.001.216, datado de 05 de novembro de 2018. Tivemos, ainda, o cuidado de garantir a assinatura dos documentos necessários à imersão nos campos de pesquisa (Termo de Consentimento Livre e Esclarecido (TCLE), Carta de Anuência e Termo de Fiel Depositário).

\section{Resultados e discussão}

\section{Conhecendo o Projeto Professor Diretor de Turma}

Em 2008, o Projeto Professor Diretor de Turma, conhecido na unidade da federação como PPDT, começou a ser implantado no Estado do Ceará. De acordo com os documentos que legitimaram a implantação do projeto e outros lançados em seguida pela SEDUC, devemos considerar que se trata de uma ação comprometida com a construção de uma escola que eduque a razão e a emoção, desmassificando o ensino e favorecendo uma articulação entre todos os segmentos que compõem a instituição escolar (gestores, professores, alunos, pais, responsáveis e a comunidade).

O Brasil tem seu primeiro contato com o PPDT em um evento científico, a saber: XVIII Encontro Estadual da Associação Nacional de Política e Administração da Educação (ANPAE), Seção do Ceará, na edição datada de 2007, quando a Prof. - Dr. ${ }^{\text {a }}$ Maria Luisa Barbosa Chaves, então Secretária de Educação do Ceará, teve a oportunidade de conhecer a experiência das escolas portuguesas, convidando a Prof. a Haidé Eunice Gonçalves Ferreira Leite, que apresentou as experiências das escolas públicas do país europeu. No mesmo evento, gestores/as escolares dos municípios cearenses Canindé, Eusébio e Madalena aceitaram o desafio de implantar as ações do Diretor de Turma sob a forma de projeto piloto, em três unidades escolares no total (CEARÁ, 2010). A experiência foi monitorada e 
acompanhada pela própria pesquisadora portuguesa e trouxe à tona resultados significativos, como se verifica em Ceará (2010), Costa e Lima (2017) e Lima (2017).

O Projeto Professor Diretor de Turma visa, como afirmado anteriormente, favorecer uma articulação entre comunidade, gestores, funcionários, professores, alunos, pais e responsáveis, implementando um trabalho educativo pautado na cooperação, no sentido de adequar estratégias e métodos de trabalho que tornem o espaço da sala de aula dinâmico e acolhedor.

Para que o projeto obtenha resultados exitosos, segundo Costa (2017), é necessária a garantia de três condições indispensáveis: uma equipe gestora que acredite em suas práticas pedagógicas; professores comprometidos, que abracem a causa do projeto e uma comunidade escolar que esteja aberta ao lançamento de um novo olhar para as mudanças que ele lança à realidade cotidiana da escola.

Sabemos que há inúmeras pesquisas que apresentam o Projeto Professor Diretor de Turma como objeto e a grande maioria delas confirma que seus impactos são visíveis e trazem respostas positivas à cotidianidade escolar, das quais podemos destacar as desenvolvidas por Leite (2015), Costa e Lima (2017) e Lima (2017). Porém, um aspecto latente em muitas destas pesquisas é que ainda há um considerável número de professores, diretores de turma (DTs) ou não, que desconhecem os papeis que o professor com tal função deve desempenhar ou nem mesmo apresentam clareza quanto a sua significação.

A expressão Diretor de Turma foi cunhada em Portugal, sendo legalmente instituída pelo Decreto-Lei no: 38/812, inicialmente como Diretor de Classe, depois normatizada por meio da portaria no: 48/578 para Diretor de Turma. Quando da implantação do Projeto Professor Diretor de Turma no Ceará prevaleceu a terminologia Professor Diretor de Turma, conforme Portaria no: 882/2010 - SEDUC/GAB, que dispõe sobre a lotação do professor diretor de turma nas escolas de ensino médio desta unidade federativa.

O diretor de turma é, assim, um professor da turma que, além de lecionar a sua disciplina/área específica, também exerce o cargo denominado de Diretor de Turma, sendo incumbido da aproximação entre os sujeitos que compõem a comunidade escolar, da promoção de clima favorável à aprendizagem e da aproximação com as famílias. Podemos dizer também que ele é responsável por exercer o “[...] papel de mediador entre a docência e a gestão, pois se, por um lado coordena um grupo de professores, por outro tem implicações diretas na gestão escolar, sobretudo a pedagógica" (LEITE, 2016, p. 2).

Corroborando com a assertiva anterior, Roldão (2007, p. 8) defende que:

\begin{abstract}
A função de director de turma incorpora um conjunto de vertentes de actuação correspondendo aos seus diversos interlocutores: alunos, professores e encarregados de educação. A actuação do director de turma junto aos alunos e encarregados de educação tende, na prática mais comum, a prevalecer sobre a acção junto dos professores que é, contudo, uma dimensão crucial deste cargo, que não pode, aliás, ser dissociada das restantes.
\end{abstract}

Para a mesma autora (ROLDÃO, 2007), o profissional que assume a referida função apresenta três demandas centrais, a um só tempo: a tarefa de gerir o desenvolvimento curricular, o papel de gestar o currículo da turma e o estabelecimento da relação funcional entre esse e os demais docentes. 
Na concepção de Leite (2016), o Diretor de Turma media três binômios indissociáveis: docência e gestão; escola e família; professor e aluno. A autora reforça, nesse âmbito, que o Diretor de Turma:

[...] é, por um lado, um docente que coordena um grupo de docentes e é, simultaneamente, um elemento do sistema de gestão da escola a quem cabem responsabilidades de caráter global do conselho de turma a que preside [...] deve ter um perfil adequado a esse cargo e vivê-lo com a intensidade e responsabilidade que lhe é inerente [...] (LEITE, 2016, p. 6-7).

É preciso atentar ainda para uma expressão bastante presente na literatura existente acerca do Diretor de Turma, que reside em "desmassificar o ensino". 0 processo de desmassificação consiste em tratar cada educando como um indivíduo único, enxergando ao longo dos processos de ensino e aprendizagem, suas dificuldades e potencialidades e, inclusive, procedendo a adequações curriculares sob a iniciativa do coletivo de professores, tanto no que se refere à turma quanto à unidade escolar, como um todo (COSTA, 2019).

\section{Diretor de Turma sob os olhares das Professoras Diretoras de Turma}

Conforme foi dito na Metodologia deste artigo, tivemos todos os cuidados necessários no sentido de garantir os procedimentos éticos firmados quando da aprovação do projeto pelo CEP/UECE. Dentre as garantias, atribuímos códigos às escolas-loci, da seguinte forma: EEEP Joaquim Filomeno Noronha como Escola Profissional 1 (EP 1) e EEEP Monsenhor Odorico de Andrade como Escola Profissional 2 (EP 2). As professoras diretoras de turma foram designadas considerando a função em exercício (Diretora de Turma (DT)), com numeração crescente, tal como no exemplo: Diretora de Turma 1 (DT 1). Para fazer uma menção o mais completa possível, a designação da professora diretora de turma sempre estará acompanhada da codificação da escola-lócus da seguinte forma: DT 2 - EP 1.

Iniciaremos nossa análise com os resultados das observações, as quais se ativeram a duas práticas pedagógicas do PPDT: aulas de Formação para a Cidadania e Desenvolvimento de Competências Socioemocionais e reuniões de Conselho de Turma, percebemos abordagens distintas nas duas unidades escolares.

As aulas observadas na EP 1 e na EP 2 acontecem em consonância com as diretrizes do projeto e atuam contribuindo para a gestão pedagógica das instituições, porém, no que se refere às reuniões de Conselho de turma, encontramos uma disparidade: na EP 1 elas estão em desacordo com o que preconiza o PPDT, não seguindo o ritual proposto pela pasta educacional do Estado e contando apenas com gestores e docentes em sua composição, o que fere a ideia de conselho como espaço plural de discussões e tomada de decisões, ao passo que na EP 2 há preocupação em seguir o ritual que é previsto para tais momentos, bem como a composição do Conselho de Turma considera os diversos segmentos da comunidade escolar (alunos, pais, professores e gestores) através das representações.

No que se refere às entrevistas, procuramos primeiramente conhecer qual a concepção de gestão pedagógica apresentada por cada uma das diretoras de turma. Destacamos duas respostas que nos dizem muito acerca de nosso problema: 
Na minha opinião, a gestão pedagógica é o coração da escola. Sem a gestão pedagógica, as coisas não fluem dentro da escola porque é núcleo gestor junto com os professores (faz gesto de união com as mãos). [...] Se não houver uma organização, uma preparação, uma elaboração, traçar um plano do que é que vai ser feito... se eles não estiverem falando a mesma língua, [...] isso reflete negativamente na aprendizagem dos alunos (DT 3 - EP 1).

[...] ela é a parte de [...] de toda a gestão da escola, de todo o funcionamento da escola. Trabalha mais diretamente com a aprendizagem do aluno, com aquilo que tiver voltado de atividade em relação ao aluno. É ligada ao objetivo principal da escola e está relacionada ao que ele precisa. [...] (DT 2 - EP 2, grifos nossos).

É possível perceber que as professoras compreendem que a gestão pedagógica é a esfera central de atuação da escola e sintetiza a sua função social. Em suas respostas é possível inferir ainda que a gestão pedagógica na atualidade é amparada na gestão democrática, sendo essencial à garantia do sucesso escolar.

Para conferir substância à análise dessa resposta, recorremos ao conceito de gestão pedagógica, a qual para Lück:

[...] é, de todas as dimensões da gestão escolar, a mais importante, pois está mais diretamente envolvida com o foco da escola que é o de promover aprendizagem e formação dos alunos, conforme apontado anteriormente. Constitui-se como a dimensão para a qual todas as demais convergem, uma vez que esta se refere ao foco principal do ensino que é a atuação sistemática e intencional de promover a formação e a aprendizagem dos alunos [...] (LÜCK, 2009, p. 95).

A autora considera a potência da gestão pedagógica afirmando que ela é apoiada e sustentada pelas demais dimensões (LÜCK, 2009).

No que tangem às relações que se estabelecem entre a gestão pedagógica e a gestão de sala de aula, a DT 2 da EP 2 afirma que:

É uma relação bem estreita [...] nós somos orientados pela gestão pedagógica. Existe uma diretriz, um Projeto Político Pedagógico, que geralmente nós construímos conjuntamente no início do ano, sendo orientados, sendo instruídos pela gestão pedagógica da escola e isso vai se refletir na sala de aula. Temos a questão do acompanhamento, do direcionamento, das discussões/reflexões acerca daquilo que está dando certo, que não está na sala de aula e, à medida em que o ano vai transcorrendo, a gente vai fazendo essa ligação, estando sempre à vontade para expor nossos pontos de vista [...] Recebendo essa orientação e tentando fazer dentro da sala de aula, em primeiro lugar, aquilo que a gente acredita, aquilo que a gente acha melhor, segundo a nossa formação e a nossa experiência também, mas prestando conta com a gestão pedagógica. A gente recebe a orientação, dá e recebe feedbacks da gestão pedagógica (DT 2 - EP 2). 
A professora demonstra clareza ao afirmar que a sala de aula, mesmo possuindo dimensão geográfica menor que a escola, também é passível de gestão e que este fazer não pode ocorrer desprovido de intencionalidade.

O exercício da função de direção de turma, no Brasil apresenta uma identidade própria, ao imprimir ligação estreita com a gestão da escola como um todo, o que impõe às professoras diretoras de turma investigadas e aos professores que ocupam o mesmo cargo funções diretamente atreladas à gestão pedagógica. Na esteira de identificar se as respondentes identificam esta relação na cotidianidade da escola, a DT 1 e a DT 2 da EP 1 declararam que:

\begin{abstract}
A gente tem todo um momento no qual a gente faz aquele monitoramento através de perguntas, de conversas em sala de aula, na relação que a gente tem com os pais. Inclusive a agente criou um grupo esse ano, um grupo de WhatsApp e estão todos os pais da nossa sala. Todas as informações são colocadas [sic] lá. Esse grupo nos aproximou mais deles. [...] A gente vai acompanhando o aluno principalmente na infrequência, que antes era feito o monitoramento só pelo núcleo gestor e hoje a gente chama a atenção toda vez que essas frequências são preocupantes. Quando é questão de nota, algum aluno está precisando de intervenção, está pendente de atividades, a gente faz um acompanhamento bem preciso mesmo e também não deixa de acompanhar a parte afetiva. [...] (DT 1 - EP 1).

[...] Nós, diretores de turma na escola ((menciona o nome da escola)), somos muito valorizados, muito ouvidos. A Gestão é muito democrática, sempre que vai tomar alguma decisão, chama os diretores de turma para ouvir a opinião de cada um, a opinião do grupo, para saber como é melhor proceder. Quando fazemos as reuniões de conselhos de classe, a gente tem liberdade de chegar e conversar com os colegas professores também. Então é uma relação horizontal e bem positiva entre a gestão e o nosso trabalho como diretores de turma (DT 2 - EP 1).
\end{abstract}

Na EP 2, uma diretora de turma fornece um importante depoimento:

[...] eu acho que antes as coisas eram muito centradas na gestão. Já com os diretores de turma, é como se tivesse vários "coordenadorezinhos" (fez sinal de aspas) dentro da escola, trabalhando em função da escola, só que compartimentalizado, cada um na sua sala. É como nós fôssemos ajudantes da coordenação. Antes a coordenação era quem cuidava de tudo, todos os conflitos, tudo ia para a gestão e hoje vai para o diretor de turma, a gente filtra, tem coisas que a gente já consegue resolver e aquilo que não está na nossa alçada, a gente parte para a coordenação e ela nos dá esse apoio. Ela nos ajuda na tomada de decisões e endossa o nosso papel. É uma parceria em favor do aluno (DT 1 - EP 2).

É possível identificar que as professoras percebem com clareza as relações entre o seu trabalho e a gestão pedagógica da escola e como cada unidade escolar cria estratégias para efetivar tal relação de maneira mais positivamente qualificada, através de iniciativas simples, como a criação de grupos de comunicação em redes sociais como o WhatsApp, para aproximar a direção de turma das famílias e encarregados da educação dos alunos. 
Procuramos saber das professoras respondentes que contribuições positivas (fortes) e aspectos negativos (fracos) elas identificam nas escolas em que atuam. No primeiro grupo, as docentes pontuam: ligação com os pais, apoio da equipe gestora escolar, intervenções pedagógicas, aproximação com os educandos e a resolução de problemas em sala de aula; enquanto como fatores questionáveis, elencam: o trabalho ainda insipiente com as competências socioemocionais, recusa a alguns instrumentais do dossiê de turma e ausência/insuficiência de formação para lidar com a amplitude de problemas vividos pelas turmas (COSTA, 2019, passim).

O Projeto Professor Diretor de Turma (PPDT) é uma iniciativa que compõe a Política Educacional do estado do Ceará desde 2008, portanto, funciona há uma década. Sua compreensão só faz sentido se o entendermos em um contexto onde também nasceram e se desenvolveram duas outras políticas: a da educação profissional e a do desenvolvimento das competências socioemocionais.

\section{Considerações Finais}

O Estado do Ceará, por meio de suas políticas públicas, tem se destacado no território nacional brasileiro, como vemos nas pesquisas de Leite (2015), Lima (2017) e Costa (2019), por implementar um trabalho tido como sério, formado por programas, projetos e ações que repercutem na aprendizagem dos alunos e no trabalho docente, assumindo uma postura pioneira e original (LIMA, 2017). Um desses projetos que é desenvolvido em suas escolas de Ensino Médio, precisamente desde o ano de 2008, é o Projeto Professor Diretor de Turma (PPDT).

0 referido projeto foi implantado inicialmente como projeto piloto, em algumas escolas do estado e gradativamente foi sendo implantado em praticamente todas as escolas estaduais, sejam elas regulares, em tempo integral ou profissionais, tipificação das escolas de ensino médio do Estado do Ceará. Assim, o PPDT é uma política que está diretamente ligada ao Pensamento Estratégico da SEDUC-CE, atuando nas seguintes linhas de frente: melhoria da aprendizagem e redução da infrequência e do abandono escolar (COSTA, 2019).

Os achados da pesquisa, oriundos das etapas de coleta e análise dos dados, permitiram-nos chegar à uma primeira conclusão: a política educacional conhecida como PPDT, no cenário da educação profissional do Sertão dos Inhamuns, não pode ser entendida sem se considerar a sua articulação com outras duas políticas educacionais de proponência do Estado do Ceará: a da educação profissional e a do desenvolvimento de competências socioemocionais. Um estudo que desconsidere essa relação certamente desconhecerá a configuração concreta do projeto, do contexto, deste objeto de estudo (COSTA, 2019).

Uma segunda consideração que deve ser feita consiste na comprovação, através de nossa pesquisa, de que o "Diretor de Turma" contribui positivamente para a melhoria da gestão pedagógica das escolas profissionais, ao desmassificar o ensino e a atenção aos alunos, tal como os documentos legais do projeto preveem. Vale ressaltar que a ideia de desmassificação é fortalecida pela presença intencional e sistemática do Professor Diretor de Turma que acompanha o aluno em todos os aspectos que compõem a sua integralidade na escola: cognitivo, comportamental, social, etc. (COSTA, 2019).

As diretoras de turma apontaram limites ao pleno trabalho do Diretor de Turma, tais como: a ausência de perfil de alguns profissionais para atuarem no cargo, o que emperra o trabalho qualificado com a gestão da sala de aula e a gestão pedagógica; a 
desproporcionalidade entre o tempo formal destinado à função e o volume de afazeres que as práticas pedagógicas demandam, em termos dos sistemas em que o/a professor/a trabalha e no cotidiano (ações) e o trabalho ainda inconsistente com as competências socioemocionais.

Mesmo com a identificação de tais dificuldades, também foram apontados fatores positivos no trabalho com o Projeto Professor Diretor de Turma (PPDT) na escola: acompanhamento positivo e sistemático do projeto pelas equipes gestoras das escolas; participação qualificada da maioria dos membros (alunos/as, pais/mães, professores/as, etc.) do Conselho de Turma nas reuniões bimestrais promovidas e presididas pelas diretoras de turma e a percepção de que as professoras investigadas são empenhadas em sua missão, apresentam visões críticas sobre o seu trabalho e o da escola de maneira geral, bem como sentem a necessidade de aprender mais sobre o projeto, apontando sugestões, como: ampliação da formação continuada, fornecimento de material diversificado para trabalho pedagógico e maior empenho de alguns/mas gestores/as escolares com o desenvolvimento do projeto (COSTA, 2019).

\section{Referências bibliográficas}

CEARÁ. Pensamento Estratégico. Disponível em: http://www.seduc.ce.gov.br/index.php/institucional/identidadeorganizacional/pensamentoestrategico > Acesso em: 10 out. 2014.

\section{$\overline{2010 .}$ \\ Chamada Pública para Adesão ao Projeto Professor Diretor de Turma. Fortaleza,}

COSTA, G. P.; COSTA, A. R. C.; MAGAlHÃES JÚNIOR, A. G. O Projeto Professor Diretor de Turma nas escolas de educação profissional do Sertão dos Inhamuns cearense à luz das ideias de Pierre Bourdieu. In: LOPES, F. M. N.; OLIVEIRA, D. R.; CASTRO, M. A.; SILVA FILHO, A. L. (Orgs.). Temas de Filosofia e História da Educação: bases teóricas e relatos experienciais. Curitiba: CRV, 2018.

COSTA, G. P. o Projeto Professor Diretor de Turma e a gestão pedagógica das escolas estaduais de educação profissional do Sertão dos Inhamuns. 2019. 157f. Dissertação (Mestrado Profissional em Planejamento e Políticas Públicas) - Centro de Estudos Sociais Aplicados, Programa de Pós-graduação em Políticas Públicas, Universidade Estadual do Ceará, Fortaleza, 2019.

o Projeto Professor Diretor de Turma e seus impactos na gestão de sala de aula: um estudo de caso na EEEP Monsenhor Odorico de Andrade, em Tauá (CE). 2017. 110f. Monografia (Especialização em Gestão Escolar e Coordenação Pedagógica) - Universidade Estadual Vale do Acaraú, Sobral, 2017.

COSTA, G. P.; LIMA, D. Os impactos do Projeto Professor Diretor de Turma na gestão de sala de aula: um estudo de caso na EEEP Monsenhor Odorico de Andrade, em Tauá (CE). Revista DoCEntes, Fortaleza, v. 2, n. 4, p. 46-56, dez. 2017.

GIL, Antônio Carlos. Como elaborar projetos de pesquisa. 5. ed. São Paulo: Atlas, 2010.

LEITE, Haidé Eunice Gonçalves Ferreira. As funções do Diretor de Turma na escola portuguesa e o seu papel no incremento da convivência. Disponível em: < 
http://www.anpae.org.br/congressos_antigos/simposio2007/169.pdf > Acesso em: 13 jul. 2016.

LEITE, Maria Cleide da Silva Ribeiro. A formação contínua do Professor Diretor de Turma no contexto das reformas do Ensino Médio. 2015. 215f. Dissertação (Mestrado Acadêmico em Educação) - Programa de Pós-graduação em Educação, Universidade Estadual do Ceará, Fortaleza, 2015.

LIMA, Vagna Brito de. Professor Diretor de Turma: um estudo entre Brasil e Portugal acerca de uma política educativa do estado do Ceará. 2017. 252f. Tese (Doutorado Acadêmico em Educação) - Programa de Pós-graduação em Educação, Universidade Federal da Paraíba, João Pessoa, 2017.

LÜCK, Heloísa. Dimensões de gestão escolar e suas competências. Curitiba: Positivo, 2009.

MINAYO, Maria Cecília de Souza (Org.); GOMES, Suely Ferreira Deslandes Romeu. Pesquisa social: teoria, método e criatividade. 34. ed. Petrópolis, RJ: Vozes, 2015.

MOREIRA, Daniel Augusto. 0 método fenomenológico na pesquisa. São Paulo: Pioneira Thomson Learning, 2004.

ROLDÃO, Maria do Céu. O Diretor de Turma e a gestão curricular. In: Centro de Investigação em Educação e Psicologia da Universidade de Évora (CIEP). Cadernos de Organização e Administração Educacional: A Turma como Unidade de Análise. Portugal: CIEP, 2007.

SALGUEIRO, António Rijo. 0 director de turma como gestor do projecto curricular: Um estudo de caso. 2010. 177f. Dissertação (Mestrado em Ciências da Educação) - Instituto de Educação, Universidade de Lisboa, Lisboa, 2010.

SILVA, Tomaz Tadeu da. Documentos de Identidade: uma introdução às teorias do currículo. Belo Horizonte: Autêntica, 1999. 